\title{
Alternativas de agregação de valor para a produção familiar: Cooperativa Amperence dos Produtores de Vinho (COOPEVI)
}

\section{Resumo}

O presente estudo consiste na apresentação de linhas de pensamentos de vários autores sobre os temas cooperativismo, desenvolvimento sustentável e agricultura familiar. As cooperativas, como veículos de políticas públicas, podem trazer força e algumas vantagens aos produtores rurais, principalmente aos produtores familiares, que são os proprietários e trabalhadores da terra. A produção familiar é hoje um segmento importante da agricultura brasileira, e, em decorrência desse fato, propôs-se estudar a relevância de uma cooperativa de vinhos no município de Ampére/PR. Os associados e produtores acreditam no desenvolvimento do setor vitivinícola da região Sudoeste do Paraná. A coleta de dados foi realizada por meio da aplicação de questionários com os produtores de uva, sócios da COOPEVI. Os dados demonstraram a importância do cooperativismo para esses produtores familiares, que buscam um espaço no mercado através da vitivinicultura. Entre os associados, a maioria tem entre 41 e 60 anos, e possuem, com predomínio absoluto, propriedades com menos de vinte hectares. Por isso necessitam se unir, para conseguir força e produzir algo diferente, a fim de se destacarem no mercado, garantindo, assim, seu lucro, já que a uva é uma atividade lucrativa e pode render até $R \$ 6.000,00$ por hectare. Na última safra, os associados da COOPEVI colheram $123.538 \mathrm{Kg}$ de uva, e a cooperativa processou parte dessa uva, produzindo 23.137 litros de vinho. Os resultados demonstraram que a cooperativa é uma boa alternativa para agregação de valor na produção familiar de uva e de vinho.

Palavras-chaves: Cooperativismo. Agricultura familiar. COOPEVI. Vitivinicultura.

${ }^{1}$ Administrador, egresso da Faculdade de Ampére (FAMPER). lucianofrank@hotmail.com

2 Administradora, Professora da Faculdade de Ampére (FAMPER), Mestranda do Programa de Desenvolvimento Rural Sustentável - UNIOESTE. keitigh@hotmail.com

${ }^{3}$ Geógrafo, Mestre em Geografia pela FCT/UNESP. Professor da Faculdade de Ampére (FAMPER). profjmarcos@hotmail.com

4 Engenheira Agrícola, Doutora em Engenharia Agrícola, Professora da UNIOESTE - MCR. adrianadegrandi@gmail.com 


\begin{abstract}
This study consists in the presentation of lines of thoughts of various authors on cooperative issues, sustainable development and family farming. Cooperatives as vehicles of public policy, can bring strength and some advantages to farmers, especially the smallholders, who are the owners and workers of the land. Family production today is an important segment of Brazilian agriculture and, as a result of this fact, we proposed to study the relevance of a wine cooperative in the town of Ampere/PR. Members and producers believe in the development of the wine industry in the Southwest region of Paraná. Data collection was conducted through questionnaires with grape growers, members of COOPEVI. The data demonstrated the importance of cooperatives for these family farmers, seeking a place in the market through viticulture. Among members, most have between 41 and 60 years, and have, with absolute predominance, properties with less than twenty acres. Why need to unite to achieve strength and produce something different in order to stand out in the market, thus ensuring your profit, since the grape is a lucrative activity and can yield up to $R \$ 6,000.00$ per acre. The last harvest, members of COOPEVI reaped 123 $538 \mathrm{~kg}$ of grapes, and sued the cooperative part of this grape, producing 23,137 liters of wine. The results showed that the cooperative is a good alternative to adding value in family production of grapes and wine.
\end{abstract}

Keywords: Cooperatives. Family farming. COOPEVI. Viticulture.

\title{
1 Introdução
}

Este estudo objetivou avaliar a relevância de uma cooperativa como alternativa de agregação de valor à produção familiar. Foi estudado o cooperativismo, para conhecer os seus princípios e valores e como ele pode ajudar no desenvolvimento sustentável, assunto tão comentado na atualidade, e, ainda, buscou-se saber se pode, de alguma forma, contribuir com os produtores familiares, mais especificamente os de uva.

Para Crúzio (2005), o cooperativismo pode auxiliar na agricultura familiar, quando possui uma administração que tem os mesmos objetivos dos produtores, buscando ser tão competitiva quanto às empresas do ramo, fazendo, assim, render cada vez mais os recursos dos seus associados. A cooperativa em estudo chama-se Cooperativa Amperense dos Produtores de Vinho (COOPEVI) e está localizada no município de Ampére/PR. Fundada em 2008, contava, em novembro de 2009, com dezenove sócios, produzindo aproximadamente 50 mil litros (por safra anual) de vinho.

Quanto à metodologia utilizada na pesquisa, tratou-se de um estudo de caso, que teve como estratégia buscar dados e ideias dos colaboradores, que foram entrevistados (por meio de um questionário) em suas propriedades, para que se sentissem mais à vontade e apresentassem da melhor forma possível, as informações sobre a propriedade, família, cooperativa, etc. Também foram coletadas entrevistas com técnicos e diretoria da cooperativa, com as quais se visou auxiliarem na construção da pesquisa.

A escolha do objeto de estudo se deu pela percepção notória da força de vontade dos agricultores - sócios e fundadores dessa cooperativa - em unir-se para solucionar algumas dificuldades com relação ao processo produtivo da uva e garantir a sua comercialização. 


\section{Cooperativismo, agricultura familiar e desenvolvimento sustentável}

Neste momento, as linhas que seguem discorrem primeiramente algumas ideias quanto à importância do cooperativismo, e, na sequência, seu valor na agricultura familiar e para o desenvolvimento sustentável. Lauschner (1994, p. 3) apresenta a importância do cooperativismo como um modelo de economia solidária:

O cooperativismo tem papel importante na agricultura, desde que foi criado vem auxiliando os agricultores a atingirem seus objetivos na lavoura. $\mathrm{O}$ cooperativismo é um modelo de economia solidária que procura maximizar o predomínio do fator trabalho sobre o fator capital. Isso significa que o cooperativismo é uma associação socioeconômica de pessoas (em certos casos, de pequenas empresas, não caracterizadas claramente como empresas de capital com fins lucrativos) que produz bens e serviços.

Segundo o mesmo autor, a cooperativa agropecuária pode reunir associados, produtores autônomos, que compram e vendem em conjunto, através de produtores ou até mesmo de cooperativas que formam unidades produtivas, exploradas pelos trabalhadores familiares. Pode-se dizer que o cooperativismo é um modelo de economia solidária, onde uns ajudam os outros, também chamada de associação socioeconômica.

\subsection{Cooperativismo e a Agricultura Familiar}

Simão e Bandeira (2014) comentam que, no início, essa prática era apenas uma produção alternativa e ocupava poucas terras. Hoje, é chamada de agricultura familiar, trazendo diversificação nas atividades agropecuárias, que são necessárias para a permanência de várias famílias no campo. Segundo Denardi (2001), os assuntos referentes à agricultura familiar são bem recentes no Brasil, tem aproximadamente dez anos. As duas principais características são a administração das atividades pela própria família e o trabalho familiar direto, muitas vezes sem a ajuda de terceiros. Pode-se dizer ainda que a agricultura familiar é uma unidade de produção e de consumo. O mesmo autor também afirma que a política agrícola está submetida às influências da macroeconomia, não deixando que os agricultores familiares tenham algum tipo de força, fazendo, assim, que prevaleçam sempre as políticas fiscal, monetária e cambial. As novas funções do espaço rural vêm do aumento de emprego nas indústrias e as demandas internas e externas que, hoje, estão exigindo a preservação da natureza e do meio ambiente.

Cremonese e Schallenberger (2005, p. 51) caracterizam agricultura familiar como:

O modelo familiar de produção pode ser caracterizado como aquele em que a direção do processo produtivo está assegurada diretamente ao proprietário da terra, onde a própria força de trabalho e a gestão da propriedade estão a cargo da mesma pessoa ou do mesmo núcleo familiar.

Baseando-se nos dados do IBGE, os mesmos autores comentam que a agricultura familiar representa uma parte importante na agricultura brasileira, ocupando aproximadamente $84 \%$ das propriedades agricultáveis do Brasil.

No Paraná, os números não diferenciam muito, são $86 \%$ das propriedades agricultáveis do estado. 
Outros dados relevantes são os números apresentados pela FAO/INCRA (apud CAPORAL; COSTABEBER, 2005, p. 10):

[...] dão conta de que os 4.140 .000 estabelecimentos rurais familiares correspondem a $85,2 \%$ do total de estabelecimentos rurais existentes no Brasil e contribuem com $38,0 \%$ do Valor Bruto da Produção, mas ocupam tão somente $30,5 \%$ da área total. Chama a atenção que $4,1 \%$ desses estabelecimentos familiares são considerados pouco integrados ao mercado. Mais grave, entretanto, é a constatação de que $39,4 \%$ dos estabelecimentos rurais familiares do país praticamente não têm renda, sendo que a maior parte deles está situada na região Nordeste.

Os autores também afirmam que são três as principais características da agricultura familiar: gestão da unidade produtiva e investimentos; trabalho desempenhado igualmente por membros da mesma família e propriedades pertencentes às próprias famílias. Compreende-se com isso que a agricultura familiar tem a característica de ser particular em todos os termos de produção e administração. Segundo Denardi (2001), as políticas públicas que influenciam a agricultura familiar são Previdência Social e Pronaf (Programa Nacional de Fortalecimento da Agricultura Familiar), sendo que a Previdência é a mais importante, pois é a responsável pela aposentadoria e pensão, que estão ao alcance de todos no país. São quase 5 milhões de beneficiados no Brasil, cujos benefícios são maiores nas regiões mais pobres e fundamentais para a economia do município. Já o Pronaf foi uma conquista dos movimentos sociais e sindicalistas dos trabalhadores rurais, fazendo com que o programa se torne uma efetiva política de desenvolvimento rural. Através do Pronaf, os agricultores conseguem financiamento de custeio de produtos, sistemas e pacotes tecnológicos tradicionais.

Lauschner (1994) afirma que a junção de vários agricultores familiares em cooperativas permite a geração de uma economia de maior escala, em nível global e local, mais forte e capaz de atingir maiores objetivos. Essa união significa integração e pode exercer funções diversas dentro do complexo rural, mantendo armazenamentos, produzindo os insumos principais e outros; podem também significar integrações que unem cooperativas de funções diversas, conforme a conveniência e os interesses de cada associado.

A cooperativa agropecuária pode reunir, como associados, produtores autônomos que compram e vendem em conjunto, através da cooperativa, ou produtores que formam unidades produtivas comuns, exploradas por trabalhadores familiares. Seja qual for o tipo de cooperativa, o cooperativismo é um modelo de economia solidária que procura maximizar o predomínio do fator trabalho sobre o fator capital (LAUSCHNER, 1994, p. 2-3).

Sobre o futuro da agricultura familiar, Lauschner (1994, p. 1) diz que "[...] o complexo rural mundial crescerá muito nos próximos anos, sem que a renda dos produtores aumente na mesma proporção", fazendo com que a agricultura familiar se fortaleça cada vez mais nas regiões, proporcionando aumento na produção de produtos adicionais. No Sudoeste do Paraná, Eduardo e Saquet (2009, p. 20) apresentam números interessantes, referentes à agricultura familiar e sua relação com as pequenas agroindústrias: 
Do total da força de trabalho utilizada nas agroindústrias em questão, 51\% é exclusivamente familiar, como apontam os dados da EMATER; $42 \%$ afirmaram utilizar mão-de-obra familiar juntamente com a contratada; e apenas $2 \%$ dos entrevistados (apenas uma ocorrência) utilizavam mão-de-obra exclusivamente contratada; $5 \%$ não responderam ao item do questionário.

Isso mostra que na região Sudoeste do Paraná a agricultura também é característica marcante, como forma de viver e organizar a produção do campo.

\title{
2.2 Cooperativismo e desenvolvimento sustentável
}

O desenvolvimento sustentável pode ajudar no desenvolvimento de sociedades cooperativas, assim como o cooperativismo pode ser uma ferramenta para a busca da sustentabilidade. Para isso, inicialmente, faz-se necessário buscar maior compreensão sobre sustentabilidade através das considerações e análises dos estudiosos do assunto. Conforme Simão e Bandeira (2014, p. 2), "[...] os conceitos de desenvolvimento sustentável e sustentabilidade são relativamente novos e derivam do conceito original de desenvolvimento". Caiden e Caravantes (apud SIMÃO; BANDEIRA, 2014, p. 2), dizem que:

\begin{abstract}
Desenvolvimento em sua forma original referia-se a um processo de revelação, de esclarecimento ou de descoberta; alguma coisa que anteriormente estava oculta ou secreta e que estava sendo devidamente revelada dentro do seu devido tempo. De acordo com os autores, com o tempo, o significado de desenvolvimento evoluiu de forma a conquistar uma dimensão de valor, ou seja, se fazia necessário além da revelação, que o resultado obtido fosse melhor com vistas ao progresso.
\end{abstract}

A comissão Brundtland (apud BUARQUE, 1999, p. 29) define desenvolvimento sustentável como "[...] aquele que satisfaz as necessidades do presente, sem comprometer a capacidade de as gerações futuras satisfazerem as suas próprias necessidades". O mesmo autor comenta que essa definição é considerada como uma resposta aos problemas de desigualdade social enfrentados, que comprometem a satisfação das necessidades de uma parcela importante da população e a preservação do meio ambiente e dos recursos naturais, fruto do crescimento acelerado e contínuo, que limita as possibilidades das gerações futuras, levando a um grave comprometimento da qualidade de vida dessas gerações que estão por vir, fazendo dessa realidade um problema global explosivo.

Simão e Bandeira (2014) afirmam que na década de 1960 surgiram as primeiras discussões e comentários sobre desenvolvimento sustentável. Nessa época, iniciou-se o processo de reflexão em relação à gravidade dos problemas ambientais e aos limites finitos dos recursos naturais. Daí para frente, o mundo todo iniciou estudos para definir um conceito para o desenvolvimento sustentável. Entre outros, em 1973, um canadense chamado Maurice Strong idealizou o conceito eco desenvolvimentista, no qual o problema do meio ambiente passou a ser entendido como um subproduto e que o processo de desenvolvimento só seria possível se somassem eficiência econômica, equidade social e equilíbrio ecológico. Quanto aos objetivos do desenvolvimento sustentável, Buarque (1999, p. 32) afirma que: 
Os objetivos do desenvolvimento sustentável envolvem relações bastante complexas entre as diversas dimensões da realidade - econômica, social, ambiental, tecnológica e institucional - com processos e dinâmicas nem sempre convergentes e combinados no tempo e no espaço.

O mesmo autor também comenta que os ganhos em algumas extensões podem levar à perda em outras, principalmente entre economia e meio ambiente, exigindo restrições no modelo de crescimento. E conclui que a participação das pessoas na vida social e política é um fator importante para a política, pois assegura a continuidade das decisões e, ainda, é um fator também importante para a qualidade de vida.

Simão e Bandeira (2014) comentam que, desde que se ouve falar, o desenvolvimento sempre esteve ligado a uma visão de progresso. Sempre em busca de poder e riqueza, o homem criou um grande desenvolvimento econômico e ainda um sistema capitalista de caráter concentrador, fazendo com que suas relações com as dimensões sociais e ambientais, que são necessárias para a promoção do desenvolvimento real, se desequilibrassem. Buarque (1999) diz que, com o crescimento da população e das atividades econômicas, ocorreu a destruição do meio ambiente e os recursos naturais, levando ao comprometimento da qualidade de vida da população e ao estrangulamento das possibilidades de desenvolvimento. Ainda os autores ressaltam a importância do cooperativismo, para atingir a sustentabilidade, apresentando como exemplo o estado do Paraná, que, no ano de 2005, possuía aproximadamente 403.195 associados em cooperativas, distribuídos em 228 cooperativas em todo o estado. A participação de pequenos e médios produtores, com área de até 50 hectares, representava aproximadamente $70 \%$ do total de cooperados, isso representa inserção social, oportunização a valorização daqueles produtores que são menos favorecidos, apresentando os fortes laços que existem entre sustentabilidade e cooperativismo. Para Buarque (1999, p. 2),

[...] Sustentabilidade e Cooperativismo possuem fortes laços de interligação, os quais permitem a identificação de diversas características comuns em termos de objetivos e interações. Nestes conceitos podem ser identificados elementos que demonstram uma preocupação com o estabelecimento de relações de equilíbrio entre agentes que interagem economicamente e socialmente em um mesmo ambiente.

Sobre a influência do cooperativismo no desenvolvimento sustentável, o autor comentam que "[...] o cooperativismo é uma alternativa para atingir o desenvolvimento sustentável, uma vez que, baseado nos seus valores e princípios, ele é um importante instrumento para o sucesso da economia de um país". (Ibidem, p. 8). Apresenta, como exemplo, o papel que as cooperativas do estado do Paraná assumiram ao investir em tecnologia e criar um elo entre agricultor e governo.

Buarque (1999) afirma ainda que o modelo de cooperativismo retrata que ainda há alternativas que priorizam outros aspectos de desenvolvimento além do econômico, mas, para isso, é importante que o pensamento da sociedade mundial evolua de ideias individuais para ideias e objetivos coletivos. Acrescenta, ainda, a necessidade de que esse modelo não fique apenas baseado em questões econômicas e atinja também o desenvolvimento social e o ambiental. 


\section{Vitivinicultura: uma alternativa para agregar valor à a produção familiar}

A vitivinicultura pode ser uma opção de produção principal ou complementar para os produtores, para que estes possam aumentar os lucros na sua produção agrícola. A diversificação da produção agropecuária também fortalece a agricultura familiar, além disso, seu processamento industrial (em associações ou cooperativas) agrega valor ao produto final.

Segundo Fontaneda (2009), no Sudoeste do Paraná, a produção de vinho aparece como um dos grandes atrativos da época atual. É uma região formada por pequenos produtores, considerados agricultores familiares, que estão fazendo cursos de capacitação e assistindo a palestras técnicas para adquirirem sucesso em sua produção da bebida e, por consequência, uma boa aceitação no mercado. Esses produtores têm como aliado um solo propício e a evolução técnica, fazendo com que os paranaenses não precisem mais ir ao Rio Grande do Sul para beber vinhos de boa qualidade. $\mathrm{O}$ autor comenta ainda que o setor vitivinícola da região passou a se desenvolver após incentivos de órgãos públicos, como palestras e cursos aos agricultores. Graças a esses incentivos, a agricultura da região apresentou a marca de 600 mil litros anuais (2008/2009), considerado um índice razoável, com grande possibilidade de aumento.

Conforme dados coletados na Prefeitura Municipal de Ampére (2009), na região Sudoeste do Paraná, existem 42 municípios e 55.764 famílias no meio rural, onde 75\% delas têm uma área menor do que 20 hectares, o que mostra que na região a agricultura familiar é um traço predominante. A região está em acelerado crescimento do processo de agroindustrialização, com a implantação de unidades familiares de processamento de frutas (uvas), para serem transformadas em vinhos, sucos, doces e outros, agregando valor ao produto e melhorando a renda das famílias rurais.

De acordo com dados apresentados pelo IBGE/Produção Agrícola Municipal (apud Instituto Paranaense de Desenvolvimento Econômico e Social - IPARDES, 2009, p. 9), em 2006, no município de Ampére, "[...] a área destinada ao plantio de uvas era de 15 hectares, com produção de 150 toneladas, com um rendimento médio de $10.000 \mathrm{~kg}$, gerando aproximadamente $\mathrm{R} \$ 114.000,00$ ". No ano de 2008, a uva era explorada em 33 municípios do Sudoeste do Paraná, dentre eles Ampére/PR, que teve uma área de 45 hectares de plantio de uva, sendo 60 os agricultores que investem nesse ramo. A uva desses agricultores é conhecida como uva americana. A produção anual, segundo a Prefeitura Municipal de Ampére (2009), gira na média de 340 toneladas, sendo 250 para mesa e 90 para industrialização, elaboração de vinho em 4 unidades produtivas, sendo uma cooperativa (COOPEVI).

Conforme informações fornecidas pela EMATER/PR, unidade de Ampére/PR, em entrevista realizada com o técnico agropecuário Rudimar,

o aumento da qualidade do vinho que é produzido na região Sudoeste do Paraná, produzido em propriedades de agricultura familiar, é decorrente de um incansável e detalhado trabalho de bastidores, quando o processamento e a tecnologia de produção são constantemente testados, isso ocorre desde 2006, através da realização de um concurso chamado Concurso Regional de Vinhos, em Francisco Beltrão. 
Também afirma que esse concurso já está na quarta edição e conta com a participação de 20 municípios, sendo 62 participantes nas categorias colonial e cantina. O vencedor é premiado com um certificado e o direito de fazer uso da sua classificação impressa na rotulagem dos vinhos da safra vencedora.

\subsection{Diagnóstico da COOPEVI e seu reflexo para os associados}

A partir da tabulação e da interpretação dos dados dos questionários, percebeuse que todos os associados da COOPEVI são do sexo masculino, sendo todos agricultores residentes no município de Ampére/PR. Quanto à idade dos agricultores associados da COOPEVI, pôde-se observar que 73,7\%, estão na faixa dos 41 e 60 anos, mas também é considerável a presença de sócios com idade superior a 61 anos, destacando-se com $21 \%$. Percebe-se uma ausência de pessoas mais jovens fazendo parte do quadro social da cooperativa. Provavelmente a ausência de políticas públicas foi um dos fatores que impediram a entrada de jovens nesta atividade, mantida por pessoas com mais idade, como uma identidade cultural de sua origem (italiana). Com relação à escolaridade dos associados, percebe-se a carência de pessoas com maior grau de estudo no grupo. 0 baixo nível de escolaridade é reflexo das suas idades (mais de $50 \%$ possuíam mais de 51 anos), já que, no passado, enfrentavam dificuldades para ter acesso às escolas. Entre os associados, apenas dois possuíam o Ensino Médio, enquanto dezesseis apresentavam apenas o Ensino Fundamental incompleto, o que pode ser uma limitação quando se trata da implantação de novas tecnologias. Entre os sócios pesquisados, $21 \%$ dos associados possuíam somente um filho; outros $42,1 \%$ estavam na faixa de dois a três filhos; $10,5 \%$, de quatro a seis a filhos, e 10,5\% possuíam de sete a nove filhos, número comum em décadas passadas, conforme afirmou um entrevistado, pois era necessário um número maior de filhos, já que o trabalho era mais braçal. Já 15,9\% não possuíam filhos. Entre o total de filhos, 52,4\% são homens e 47,6\% são mulheres.

Por meio do questionário também se procurou levantar o número de pessoas que trabalham na propriedade e a média de horas diárias. Em geral, $21 \%$ das propriedades tinham uma pessoa da família como trabalhador permanente, $43 \%$ das propriedades possuíam dois trabalhadores, $26,3 \%$ das propriedades pesquisadas tinham três trabaIhadores e 10,5\%, de quatro a cinco trabalhadores na propriedade, sendo que a média de horas trabalhadas é 8 horas e 30 minutos diários. No geral, as horas de trabalho não seguem uma regra; nos períodos de plantio e colheita, é trabalhado mais horas, e, em outros momentos, esse número é menor. Além disso, percebe-se que a jornada média de trabalho diária se assemelha com aquela dos trabalhadores urbanos. Com relação ao tamanho das propriedades, percebe-se que 42,1\% delas têm de 11 a 20 hectares, no geral, entre os dezenove associados, quinze possuíam propriedades com área inferior a 20 hectares, destas, dois possuíam área inferior a 5 hectares, evidenciando que a produção de uva e vinho pode viabilizar pequenas áreas de terra. Concluímos, então, que as propriedades dos associados são consideradas pequenas, de regime familiar.

Foi fundamental na pesquisa identificar qual a área do parreiral dos associados. Pôde-se observar que 63,1\% dos entrevistados possuíam apenas 1 hectare de parreiral, e 15,9\% apenas 0,5 hectare. Esse número reduzido da área de parreiral é destaque de- 
vido às propriedades dos associados em geral também serem pequenas, porém uma pequena propriedade, com 1 hectare de uva plantada, chega a colher $8.000 \mathrm{~kg}$, tendo um faturamento em torno de $\mathrm{R} \$ 6.000,00$, o que acaba sendo muito significativo para um agricultor familiar, já que 1 hectare de soja, por exemplo, cultivo que predomina em nossa região, teria um faturamento em torno de $\mathrm{R} \$ 2.000,00$.

Sobre a mão-de-obra empregada nas propriedades, os associados não possuíam assalariados permanentes, $57,7 \%$ contam com diarista, no período da colheita, e 42,1\% utilizam apenas a mão-de-obra familiar. Sobre as trocas de dias com vizinhos, uma modalidade de trabalho cooperativo que não envolve valores, 36,9\% realizaram trocas de dias na colheita, e 63,1\% não realizaram essas trocas, percentual próximo ao dos agricultores que possuem diaristas durante a colheita. Observou-se também que 36,9\% possuíam trator, $31,6 \%$ acompanhados por arado e $26,3 \%$ com pulverizador, o que acaba facilitando a produção e o cultivo dos produtos. Com isso, acabam sendo denominados agricultores modernos (utilizam tração mecânica) e até podem prestar serviço para vizinhos e obter um ganho extra. Por outro lado, 57,7\% dos associados possuíam tração animal e arado para tração animal; 42,1\% possuíam grade de tração animal, e 89,5\% possuíam enxada e pulverizador manual para os auxiliares no cultivo dos produtos. Sendo assim, a maioria deles são agricultores que utilizam métodos mais tradicionais no preparo e manejo de suas lavouras, efetuando um trabalho mais manual.

A produção de uva comercializada pelos associados da COOPEVI, na safra de 2008/2009, foi de $123.538 \mathrm{~kg}$, mas apenas $28.468 \mathrm{~kg}$ foram comercializados na cooperativa. Como a maioria dessa produção é da uva Niágara, a própria COOPEVI não faz questão de receber grande quantia da mesma; além disso, o vinho produzido por esse tipo de uva (mesa) tem pouca aceitação no mercado. Outros $75.400 \mathrm{~kg}$ foram comercializados com outros estabelecimentos (mercados, atacados e nas casas), e isso acontece devido ao fato dessa uva ter uma boa aceitação para consumo in natura, e os produtores recebem o pagamento à vista, chegando a receber $\mathrm{R} \$ 1,50$ por $\mathrm{kg}$, valor bem superior ao que receberiam da cooperativa. E, ainda, os outros $24.270 \mathrm{~kg}$ são destinados para a produção de vinho em casa. Para os agricultores que já produziam um bom vinho e tinham um mercado formado, acabou se tornando mais lucrativo manter a atividade, também como uma forma de aproveitar aqueles cachos de uva que não possuem boa aparência, mas uma boa maturação, o que favorece a produção de um vinho de qualidade. Além disso, é difícil vender os cachos 'ditos' mais feios no mercado, e $20 \mathrm{~kg}$ de uva transformada em vinho chega render ao produtor $\mathrm{R} \$ 50,00$, percebendo-se, então, que é uma forma de aproveitar a matéria-prima disponível na propriedade. No geral, quase $52,5 \%$ da produção dos associados é vendida fora da cooperativa, 21\% para a mesma e 15,9\% para produção de vinho em casa.

Além da produção voltada para o mercado, todos os associados possuíam, na propriedade, frutas, hortaliças, mandioca e suínos; $68,4 \%$ dos associados produzem batata doce; $10,5 \%$ produzem batata inglesa; $63,1 \%$ têm frango caipira; $47,6 \%$ produzem amendoim; $52,4 \%$ têm produção de mel; $15,9 \%$ produzem arroz; $63,1 \%$ produzem pipoca; $21 \%$ produzem milho e feijão. Em geral, possuem uma boa diversidade de produtos voltados para o consumo da própria família, o que também auxilia na redução dos custos com alimentação (feira, mercado). Quanto às terras que atualmente são ocupadas com o 
cultivo da uva, para quatro dos entrevistados, antes eram utilizadas no cultivo do feijão e do milho; para três deles, eram para o cultivo do milho; para dois, milho e soja; para outros quatro, essas terras serviam como pasto; outros dois também citaram o cultivo da soja; um mencionou milho e mandioca; outro, milho e fumo; outros dois revelaram que as terras eram destinadas às plantações de milho e pasto e mandioca, respectivamente. Ao que parece, produtos como feijão, milho, soja e fumo, que antes eram voltados para o mercado, perderam espaço para o cultivo da uva, já que essa apresenta maiores rendimentos em pequenas áreas, ao contrário dos produtos tradicionais (milho e soja), que precisam de grandes áreas para apresentar viabilidade. Sobre as condições de acesso à propriedade, nove $(47,6 \%)$ dos entrevistados responderam que elas se encontravam em boas condições; para quatro, estavam em condições médias; para outros quatro, eram regulares, e para dois encontravam-se em péssimas condições de acesso.

O questionário também procurou levantar as outras rendas das famílias entrevistadas: oito $(42,1 \%)$ responderam que não possuíam assalariados fixos, ou seja, a renda obtida era somente a das atividades agropecuárias; quatro famílias recebiam duas aposentadorias do INSS; uma família possuía dois assalariados (filhos que trabalham em empresas na cidade); duas famílias têm apenas um assalariado, outras três famílias têm uma aposentadoria, e uma família tem uma aposentadoria e um assalariado. Portanto já existe um número considerável de associados aposentados por idade, o que também é garantia de uma renda fixa mensal, para manter o custo de vida da família, e também ajuda a manter a atividade da vitivinicultura e a cooperativa, já que muitas famílias não dependem desta renda para sobreviver.

Sobre a relação dos associados com a cooperativa, a maioria dos entrevistados (14) são sócios há 4 anos, ou seja, desde 2005; outros quatro fazem parte da COOPEVI há 5 anos, desde 2004; um deles é sócio há 3 anos, desde 2006; um é sócio há 7 anos, desde 2002, quando iniciaram os projetos pensando na implantação da vinícola. Quanto aos motivos de terem se associado à cooperativa, treze deles, que representam $68,4 \%$, disseram que foi pela garantia de mercado para sua uva; outros cinco entrevistados, que representam $26,3 \%$, acreditavam na união, que gerasse força para a aquisição de melhorias para fortalecer o negócio, e um deles, que representa 5,3\%, acreditava na transformação do produto, no sentido de agregar valor ao produto final.

Com relação à participação em reuniões bem como nas tomadas de decisões da cooperativa, todos afirmaram participar, treze associados já foram representantes de algum segmento da direção da COOPEVI, ou seja, 68,4\%; outros seis sócios ainda não fizeram parte da direção. Como o número de sócios é reduzido, a maioria deles geralmente ocupa alguma função na direção de cooperativa. Quando foram perguntados sobre as vantagens de serem sócios da COOPEVI, dez sócios destacaram como vantagem a assistência técnica, representando 52,4\%; já para sete deles, 36,9\%, a garantia de mercado; para um deles a vantagem é ser sócio de um grupo forte, e para um deles, não existe vantagem em ser sócio da cooperativa.

Focando na gestão da COOPEVI, conforme entrevista com o Sr. Vladimir Pelissari, vice-presidente (técnico em agropecuária da prefeitura de Ampére/PR), em novembro de 2009, a cooperativa é organizada e administrada da seguinte forma: ela conta com dezenove associados, que são os colaboradores, funcionários e administradores do seu 
próprio negócio. A diretoria da COOPEVI é formada por presidente, vice, associados e uma secretária. Todos os sócios participam das reuniões uma vez por mês, para discutir assuntos de funcionamento, giro do mês e decisões a serem tomadas; já a secretária trabalha em período integral, fazendo controles e vendas, sendo paga pela prefeitura municipal. Existem também quatro pessoas do conselho fiscal, que são responsáveis por efetuar a fiscalização financeira e administrativa mensalmente. Também afirmou o entrevistado que possuem um vendedor, para fazer praça na região Sudoeste do Paraná, e um representante no Mato Grosso, estado que tem maior aceitação pelo vinho suave. A divulgação na região é feita pela Rádio Ampére, do próprio município, na rádio da cidade vizinha de Realeza e na rádio FM de Barracão (Fronteira FM). Informou ainda que a cooperativa está há três anos na atividade, sendo que já passou por várias dificuldades, mas, através de investimentos próprios, ou seja, recursos obtidos diretamente das vendas do vinho, conseguiu se recuperar.

No último ano, foi expandida em 5 alqueires (12,1 hectares) a produção de uvas finas, por pretenderem entrar no mercado de vinhos finos. Os sócios trabalham de domingo a domingo, quando é época de safra, e, quando não há safra, trabalham numa escala de segunda, quarta e sexta-feira. Cada um dos sócios possuía uma cota de $\mathrm{R} \$ \mathbf{2 . 0 0 0 , 0 0}$ para giro. Como a concentração de vendas é no inverno, a cooperativa faz a venda em outras datas do ano para empresas que queiram presentear seus empregados com o seu logotipo. Fazendo isso, conseguem expandir as vendas para outras regiões, e, por ser a única da região com registro, consegue fazê-lo com um preço competitivo. A Cooperativa é uma das mais sofisticadas do Paraná, possui laboratório próprio para efetuar análise dos vinhos e até presta serviço de análise para interessados. Portanto, a COOPEVI conta com uma estrutura adequada, com capacidade para analisar a qualidade do seu próprio vinho, reduzindo gastos com esse processo.

O produto recebido pela COOPEVI, diretamente dos seus produtores e sócios, é a uva. Durante as duas últimas safras (2008/2009), receberam uvas das espécies bordô: 29.218 kg; Niágara rose: 12.433 kg; Niágara branca: 978 kg; Moscato: 5.606 kg; Poloski: 3.320 kg; Merlot: 1.666 kg e Bayley: 18.496 kg. A COOPEVI produz hoje os vinhos das uvas citadas acima, além de também produzir uma pequena quantidade de suco da uva rose, que não é fabricado todos os anos, apenas em algumas safras. As diferenças ocorridas entre as safras são influenciadas, principalmente, pelas variações do tempo e os cuidados dos produtores com o parreiral. Os associados estão satisfeitos com os resultados (lucros) que a produção de vinho vem apresentando; além disso, também acreditam no crescimento da cooperativa. Entre a safra de 2008 e 2009, o crescimento da produção foi de 3.242 litros, $5.403 \mathrm{~kg}$ de uva. Com relação ao tipo de uva e de vinho, em ambos os anos, o destaque foi para a uva Bordô, que produz um vinho tinto, bastante apreciado na região. Em média, para cada quilo de uva, são produzidos $600 \mathrm{ml}$ de vinho ou suco.

A produção de vinhos da COOPEVI ainda é muito recente. A pouca cultura de consumo de vinhos de melhor qualidade é um fator que ainda prejudica a expansão dos negócios, mesmo assim, conforme informações da secretária da cooperativa, em 2009, possuía aproximadamente 100 (cem) clientes, com mercado basicamente limitado à região Sudoeste do Paraná, a maior parte ao município de Ampére e o restante aos municípios de Santa Izabel do Oeste, Realeza, Salto do Lontra, Nova Esperança do Sudoeste, 
Pinhal de São Bento, Pérola do Oeste e Pranchita. Além disso, como a COOPEVI está localizada às margens da BR-182 (uma das ligações entre o Sul, Sudeste e Centro-Oeste do Brasil), muitas pessoas de outras cidades e estados que estão de passagem também acabam adquirindo vinhos em menor quantidade.

A cooperativa também está expandindo sua área de comercialização na busca de novos mercados, alguns estabelecimentos comerciais e revendedores do Mato Grosso e Minas Gerais já compraram vinhos da marca Ampevi, que, para o início, foi um número significativo, em torno de 600 litros para cada destino. Isso significa que a cooperativa, com o empenho dos associados, está firmando-se na atividade, agregando valor à produção de uva dos cooperados e contribuindo para o desenvolvimento local sustentável.

\section{Conclusões}

Com esta pesquisa, percebeu-se que as cooperativas não são algo recente, surgiram de povos mais antigos, trabalhadores humildes que buscavam refúgio para as ameaças do capitalismo. Com união e organização, a agricultura familiar vem se destacando e ganhando novos espaços através de parcerias com governos, na dinamização de políticas públicas. O cultivo da uva e a produção de vinho estão ganhando espaço através de cooperativas vitivinícolas, apresentando-se como uma alternativa sustentável para a agricultura familiar.

Objetivando avaliar a relevância da COOPEVI, como uma alternativa de agregação de valor à produção familiar de uva, pode-se perceber que ela conta atualmente com uma boa estrutura, resultante de projetos (políticas públicas estaduais e federais) e do trabalho de seus associados, que se empenharam para o fortalecimento dessa cooperativa. Seus produtores são de porte pequeno e médio, caracterizando uma agricultura familiar, traço comum no Sudoeste do Paraná. Foi diagnosticado que a produção de uva é feita em pequena quantidade e, somando a produção de cada produtor, chega-se a uma quantidade relevante para a produção do vinho. O processo de fabricação é feito pelos mesmos produtores e sócios da COOPEVI. Observa-se também que o funcionamento e organização da cooperativa são da responsabilidade dos sócios e de uma funcionária (cedida pela Prefeitura através de parceria). A participação de todos os associados é um destaque fundamental na relação entre a cooperativa e os cooperados.

Respondendo ao problema da pesquisa, que é avaliar se a COOPEVI pode ser considerada uma alternativa de agregação de valor à produção familiar de uva, observou-se, no decorrer do estudo, que a produção de uva pode render aproximadamente $\mathrm{R} \$ 6.000,00$ por hectare, enquanto a produção convencional (milho, trigo, soja) talvez não ultrapassasse $\mathrm{R} \$ 2.000,00$. Portanto, dados como esse revelam que a cooperativa é uma alternativa para agregação de valor na produção familiar de uva e sua transformação em vinho. Portanto, os objetivos propostos foram atingidos. Através de pesquisa bibliográfica, questionários e entrevistas com os envolvidos na COOPEVI, apresentou-se informações sobre a cooperativa, os associados, a produção de uva dos cooperados, o funcionamento e a organização da cooperativa; a relação da cooperativa com os associados e a produção de vinhos da COOPEVI, bem como seus principais destinos de comercialização. Enfim, cabe destacar a boa vontade e disponibilidade dos associados em colaborarem. 
Pode-se afirmar que este estudo serviu para entender a dinâmica de funcionamento de uma cooperativa de vinhos no município de Ampére - PR, e ainda contribuiu com uma pesquisa sobre a temática do cooperativismo e, finalmente, sugere-se que a cooperativa invista um pouco mais na divulgação do produto, podendo, assim, atingir novos mercados, tornando-se cada vez mais competitiva. Também se sugere que legalizem o produto secundário (suco de uva, para terem dois tipos de produtos, com pico de vendas no inverno (vinho) e no verão (suco). Dessa forma, teriam faturamento mais regular durante o ano todo, e, ainda, se indica que sejam elaborados outros trabalhos científicos referentes a este assunto, no sentido de acompanhar e contribuir com o desenvolvimento regional.

\section{Referências}

BUARQUE, Sérgio C. Metodologia de planejamento do desenvolvimento local e municipal sustentável. Brasília: INCRA/IICA, 1999.

CAPORAL, F. R.; COSTABEBER, J. A. Agroecologia e segurança limentar. Revista Ação Ambiental, Viçosa, ano 7, n. 31, p. 8-11, maio/jun. 2005.

CREMONESE, Camila; SCHALLENBERGER, Erneldo. Cooperativismo e agricultura familiar na formação do espaço agrícola do oeste do Paraná. Tempo da Ciência. Cascavel, n. 12, v. 23 . pp. 49-63, 1. sem. 2005.

CRÚZIO, Helnon de Oliveira. Como organizar e Administrar uma cooperativa: uma alternativa para o desenvolvimento. 4. ed. Rio de janeiro: FGV, 2005.

DENARDI, Reni Antonio. Agricultura familiar e políticas públicas: alguns dilemas e desafios para o desenvolvimento rural sustentável. Agroecologia e Desenvolvimento Rural Sustentável. Porto Alegre, n. 3, jul./set., 2001.

EDUARDO, Márcio Freitas; SAQUET, Marcos Aurélio. O Agroartesanato no sudoeste paranaense: a marca histórica de uma formação territorial. XIX Encontro Nacional de Geografia agrária. São Paulo: UNESP, 2009.

FONTANEDA, Roberto. Sudoeste do Paraná. 2009. Disponível em:

< http://tudosac.blogspot.com.br/2009_07_01_archive.html >. Acesso em 10 out. 2014.

IPARDES. Instituto Paranaense de Desenvolvimento Econômico e Social. Caderno Estatístico Município de Ampére. Curitiba: IPARDES, 2009. Disponível em: <hppt://www.ipardes.gov.br>. Acesso em: 23 nov. 2009.

LAUSCHNER, R. Cooperativismo e Agricultura Familiar. EMBRAPA, 1994. Disponível em: <http://gipaf.cnptia.embrapa.br/publicacoes/artigos-e-trabalhos/lauschner94.pdf>. Acesso em: 10 out. 2014.

PREFEITURA MUNICIPAL DE AMPÉRE. Ampére: Pólo Industrial. Ampére, 2009.

SIMÃO, Ângelo G.; BANDEIRA, Arnaldo. O cooperativismo como alternativa para o atingimento da sustentabilidade. Disponível em:

<http://www.unifae.br/publicacoes/pdf/sustentabilidade/angelo_arnaldo_ cooperativas.pdf>. Acesso em: 5 set. 2009. 